\title{
Medical negligence: Alternative claims resolution an answer to the epidemic?
}

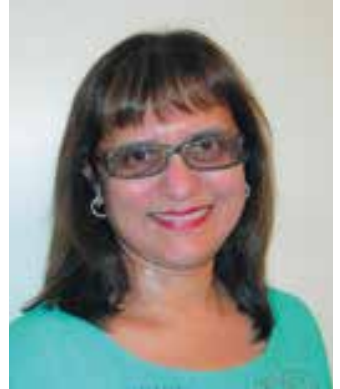

Ames Dhai

Editor

amaboo.dhai@wits.ac.za
The price paid by society because of unreasonable medical negligence claims cannot be ignored. While medical malpractice systems in the country are exorbitantly costly, they are also inefficient. This impacts directly on access to healthcare, a basic human right in the country as enshrined in section 27 of the Bill of Rights of the Constitution of South Africa (SA). ${ }^{[1]}$ Practising defensive medicine, irrespective of the sector in which healthcare is delivered, has now become the norm, with the focus being not just patient health and best interests, but also that of safeguarding against possible medical malpractice liability, thereby increasing unnecessary clinical and diagnostic procedures. The unequivocal situation is that currently the fear of lawsuits holds hostage practitioners' options and preferences for delivery of ethically exercised care to their patients, leading to frustration and dissatisfaction both to practitioners and patients. ${ }^{[2]}$ Moreover, a culture of blame is also now pervasive.

While the Medical Protection Society (MPS) has over the past 6 years witnessed deterioration in their overall claims environment in the country, it does not believe that the situation is owing to a decline in professional standards. Several complex factors, some of them positive, are attributed to the current state of affairs. According to the MPS, these include the fact that robust, patient-centered complaints systems are lacking, thereby leaving litigation by patients as the only viable avenue for redress. Delays are endemic because of the lack of efficient and predictable legal processes for the handling of clinical negligence claims. Claim sizes have therefore increased. The costs of settling claims also increase with protracted legal processes. Attorneys have refocused their interest areas towards personal injury and, in particular, clinical negligence claims following amendments to the Road Accident Fund Act. ${ }^{[3]}$ Protections for patients in terms of their rights in the Constitution and the Consumer Protection $\mathrm{Act}^{[4]}{ }^{[4]}$ coupled with increasing patient expectations with regard to greater involvement in and understanding of their healthcare, while positive, have also contributed to the upturn in the frequency of claims. The MPS further states that the clinical negligence system currently in place does not facilitate efficient and fair resolution of disputes. Rather, it is adversarial, time-consuming, expensive, lacks transparency and frequently gives rise to 'trial by ambush'.[5]

The situation in SA reflects the experience of practitioners in many parts of the world. Various approaches towards addressing the problem have been considered and embarked upon, and alternative claims resolution (ACR) has been proposed by many. ${ }^{[2]} \mathrm{ACR}$ approaches include non-judicial, specialised health courts systems with specialised judges and state-appointed neutral experts to systematically adjudicate claims. Medical review and screening panels to weed out frivolous complaints and encourage swift settlement of meritorious claims have also been proposed. Peer review of expert testimony could be considered in order to curb the number of experts who are willing to make dogmatic statements irrespective of bias. Negotiation and mediation as a form of ACR are valuable considerations as well. Negotiation is when two or more people work together towards mutually agreeable outcomes by creating a deal or resolving a conflict. Mediation is '... facilitated negotiation in which the parties involved in conflict meet in the presence and with the assistance of an impartial third party called the mediator! ${ }^{[2]}$ In this issue, Judge Claassen explains the merits of embarking on a process of mediation rather than litigation for medical negligence claims. ${ }^{[6]}$

Greater disclosure of medical errors has been advocated by many. ${ }^{[2,5]}$ This approach is supported as it is good ethical practice and enhances the patient-practitioner trust relationship. However, a major and realistic fear with the method proposed is that open and honest disclosures could facilitate further medical negligence claims. In some countries apology laws have been enacted to protect statements of apology made by medical practitioners by excluding the use of these apologies as evidence in medical malpractice litigation. Emerging evidence does show that in such situations malpractice claims have been dramatically reduced by up to $47 \%$ in compensation payments and settlement times have been reduced to about 6 months. It has also been shown that apology laws have helped with expediting the resolution process and decreasing the claims frequency. ${ }^{[2]}$

Other forms of reform include staggered payments of damages should the award exceed a predefined threshold and the capping or limiting of claims on noneconomic and punitive damage. While medical insurance premiums have been shown to be kept down in countries where capping has been implemented, varied results have been found as regards claims and payouts for noneconomic damages. ${ }^{[2]}$ In the USA, 29 states have introduced a limit on damages. Limits range from USD250 000 in California to USD750 000 per incident in Tennessee and Wisconsin. A reported 19\% decrease in the average value of noneconomic claims coupled with a decline from $4 \%$ to $1.4 \%$ in the probability that a case would be brought to court is promising with regard to limiting frivolous lawsuits and keeping down the costs of healthcare by capping claims. ${ }^{[5]}$ However, limiting payouts must not erode the principle of fairness and patients have to be adequately reimbursed for damages legitimately claimed for. Controversy in the USA over this process has led to legal challenges, and seven states have had their Supreme Courts revoke capping as unconstitutional. ${ }^{[5]}$ Instead of merely capping claims, reducing monetary incentives for attorneys by limiting their fees should 
be included in legal reform. This could include a sliding scale fee schedule that reduces contingency fees or a peer review process when contingency fees are charged. ${ }^{[2]}$

Early in 2015, Dr A Motsoaledi, the Minister of Health (MoH) of SA convened a Medico-Legal Summit where much of the above was highlighted. In addition, inherent systems failures in the public healthcare sector were underscored as contributing to the escalating frequency of malpractice and negligence claims against the state. ${ }^{[7]}$ An outcome of the Summit was the establishment of a ministerial medico-legal task team to develop a declaration which would assist with addressing this SA crisis. The MedicoLegal Summit declaration was signed into effect on 15 March this year by the $\mathrm{MoH}$. The declaration addresses three categories of concerns: patient safety, administrative and legal. Implementation of the resolutions in the declaration will utilise a phased approach - immediate, medium term and long term. The task team has planned a process whereby provincial heads will be engaged in implementing this declaration. It is hoped that with time the culture of blame will evolve into a culture of patient safety irrespective of the sector in which healthcare is delivered.
Acknowledgements: I would like to thank Dr Terence Carter, Deputy Director General of Health and the medico-legal task team for giving me permission to report on the Declaration.

\section{References}

1. Republic of South Africa. The Constitution of the Republic of South Africa. Pretoria: Government Gazette, 1996.

2. World Health Organization. Rapid Scoping Review of Medical Malpractice Policies in Obstetrics. Geneva: World Health Organization, 2015. www.whoreport_malpracticemodels_-12aug2015_final.pdf (accessed 1 May 2016).

3. Republic of South Africa. Road Accident Fund Amendment Act 19. Pretoria: Government Gazette, 2005.

4. Republic of South Africa. Consumer Protection Act 68. Pretoria: Government Gazette, 2008.

5. Medical Protection Society. Challenging the Cost of Medical Negligence. The Case for Reform. London: Medical Protection Society, 2015. http://www.medicalprotection. org/docs/default-source/pdfs/Booklet-PDFs/sa-booklets/challenging-the-cost-ofclinical-negligence---the-case-for-reform.pdf?sfvrsn=4 (accessed 1 May 2016)

6. Claassen N. Mediation as an alternative solution to medical malpractice court claims. S Afr J BL 2016;9(1):7-10. DOI:10.7196/SAJBL.469

7. Dhai A. Medico legal litigation: Balancing spiraling costs with fair compensation. S Afr J BL 2015;8(1)2-3. DOI:10.7196/SAJBL.407

SAfr J BL 2016;9(1):2-3. DOI:10.7196/SAJBL.474 